\title{
A Review on Hydrodynamic Cavitation - A Promising Technology for Soil and Water Conservation in Inceptisol of North West IGP
}

\author{
M. Sharath Chandra ${ }^{1 *}$, R.K. Naresh ${ }^{1}$, N.C. Mahajan ${ }^{2}$, Rajendra Kumar ${ }^{1}$, \\ Arvind Kumar ${ }^{3}$, S.P. Singh ${ }^{4}$, Yogesh Kumar ${ }^{5}$ and Rahul Indar Navsare ${ }^{5}$
}

${ }^{1}$ Department of Agronomy, Sardar Vallabhbhai Patel University of Agriculture \& Technology, Meerut, U.P., India

${ }^{2}$ Department of Agronomy, Institute of Agricultural Sciences, Banaras Hindu University, Varanasi, U. P., India

${ }^{3}$ Barkatullah University Bhopal, M.P., India

${ }^{4}$ KVK, Shamli, Sardar Vallabhbhai Patel University of Agriculture \& Technology, Meerut, U.P., India

${ }^{5}$ Department of Soil Science \& Agricultural Chemistry, Sardar Vallabhbhai Patel University of Agriculture \& technology, Meerut, U.P., India

*Corresponding author

\section{A B S T R A C T}

Keywords

Hydrodynamic cavitation, Cavitation Bubble extensional viscosity polyethylene oxide, Advanced Oxidation Process (AOP)

Article Info

Accepted:

07 July 2019

Available Online:

10 August 2019
Hydrodynamic cavitation is a technology for the conservation of soil and water and waste water treatment due to its simple reactor design and capacity in large- scale operation. When fluid's local pressure reaches a level lower than the saturation vapour's pressure at environment temperature, cavitation bubbles begin to grow and together with fluid flow are driven to the points with high pressure where they are quickly collapsed. The potential of hydrodynamic cavitation as an advanced oxidation process (AOP) for wastewater treatment, showing its suitability and efficiency against a wide variety of contaminants and concentrations, with very low operation costs, simple equipments and no reactants required. In the review paper related to hydrodynamic cavitation and its techniques for the soil and water conservation and use of associated processes in water and effluent treatment technologies will be discussed.

\section{Introduction}

Hydrodynamic cavitation is a process intensification technique that creates nanometer sized cavitation bubbles due to a turbulent pressure field created by welldesigned orifice structures (Fig. 1). Hydrodynamic cavitation describes the process of vaporization, bubble generation and bubble implosion which occurs in a flowing 
liquid as a result of a decrease and subsequent increase in local pressure. Hydrodynamic cavitation can be produced by passing a liquid through a constricted channel at a specific flow velocity or by mechanical rotation of an object through a liquid. In the case of the constricted channel and based on the specific (or unique) geometry of the system, the combination of pressure and kinetic energy can create the hydrodynamic cavitation cavern downstream of the local constriction generating high energy cavitation bubbles. The process of bubble generation, and the subsequent growth and collapse of the cavitation bubbles, results in very high energy densities and in very high local temperatures and local pressures at the surface of the bubbles for a very short time. Cavitation in hydraulic machines negatively affects their performance and may causes severe damages. The management of the small hydropower plants for achieving higher efficiency of hydro turbines with time is an important factor, but the turbines show declined performance after few years of operation as they get severely damaged due to various reasons. One of the important reasons is erosive wear of the turbines due to high content of abrasive material during monsoon and cavitation. Cavitation commonly occurs in hydraulic turbines, around runner exit and in the draft tube. In general there are two ways to reduce the cavitation damage.

Wastewater discharge from industrial units containing newer and refractory chemicals is a significant problem for conventional treatment plants. The release of this toxic wastewater into the natural environment is not only hazardous to aquatic life but also creates significant environmental concerns. Conventional wastewater treatment methods like adsorption on activated carbon, extraction, and chemical oxidation have limitations such as limited applicability and lower efficiency (Gogate. 2010). The hydrodynamic processes, cavitation occurs in a flowing liquid during a fall in the static pressure, caused by flow conditions or external influences (Shah et al., 2012). It is commonly produced in constricted or curved channels and also as a result of motion of bodies in a liquid such as a ship's propeller. Cavitation offers two important advantages over conventional AOPs due to the fact that neither reactants nor UV light are used: first, it requires significantly lower operation costs than the rest of the AOPs; and second, the byproducts are limited to those expected from the oxidation of the contaminants, avoiding the presence of other dangerous oxidants such as chlorine (Benito et al., 2005). Thus, this type of cavitation appears as a result of a local constriction to the flow path of the liquid or the detachment of the stream from the surface of streamlined bodies. Hydrodynamic cavitation can be innovated and prefers an energy efficient way of generating cavitation (Arrojo and Benito, 2008).

\section{Hydrodynamic cavitation process}

Cavitation forms and develops in a flowing liquid through zones, in which the pressure of the liquid falls below a critical value, normally close to the saturated vapour pressure at a given temperature for the liquid. The value for this pressure is dependent not only on the type of liquid, but also on the amount of pollutants such as micro-particles or macro-particles, and micro-bubbles containing incompletely dissolved gases (Ozonek. 2012). The cavitation process is very complicated and many attempts have been made to theoretically explain the mechanism of its creation. Cavitation is a dynamic process, dependent on continuous changes over time to the volume and geometry of the bubbles and cavities. The timescale for this is in the order of milliseconds. After moving through the cavitating liquid into regions exceeding the critical pressure, the bubbles and cavities 
undergo sudden implosions in time periods significantly smaller than milliseconds, thus creating a local rise in pressure in different zones of the region. Locally, the pressures in the liquid can reach values of hundreds, and even thousands of megapascals. Characteristic effects which accompany the cavitation bubble implosions are hydrodynamic, mechanical, acoustic, chemical, thermal and even electrostatic. If the cavitation occurs by pressure variation in the flowing liquid due to the presence of throttling devices such as venturi, orifice etc., it is called as hydrodynamic cavitation.

\section{Hydrodynamic cavitation reactor}

The intensity of the technological processes in hydrodynamic cavitation devices is associated with a range of physicochemical and mechanical effects (shock waves, cumulative microstreams, self-excited oscillations, turbulence), caused by the implosion of cavitation bubbles. In turn, this leads to a concentration of bubbles and an increase in their energies, located near the centre of the cloud. Under such conditions, during an implosion, the pressure rises to almost an order of magnitude greater than during the implosion of a single bubble. Intensive shock waves in the system lead to a pressure increase at the centre of the bubble. If a significant increase in the surface area of the phase transition boundary repeats, the chemical composition of the system changes. These effects, due to the large concentration of cavitation bubbles, lead to favourable conditions for the initiation of physicochemical processes, which under normal conditions are complex or difficult to conduct.

There are three main factors that specify the formation of the hydrodynamic cavitation field and the effectiveness of the cavitation process (Fig. 2).
The first group consists of parameters such as the size and shape of the cavitation inducer and the flow chamber which determine the structural characteristics of the reactor. The second group consists of parameters which characterize the liquid medium in general: viscosity, density, surface tension and the dissolved gas contents. The third group includes the technological process parameters; the "processing" time (the number of times which the medium passes through the cavitation region) and the interdependence between temperature and pressure of the process (Ozonek and Lenik 2011). The technological effectiveness of the cavitation process depends on the cumulative effect of the parameters. The range of the cavitation process parameters particularly the number of cavitation bubbles and their implosion conditions is quite extensive (Ozonek and Lenik, 2011). The magnitudes of the pressures and temperatures during bubble collapse, as well as the number of free radicals at the end of cavitation, are strongly dependent on the operating conditions and configuration of the hydrodynamic cavitation reactors (Gogate and Pandit, 2005). The most important parameters which affect the cavitation process intensity are shown in Table 1.

Moreover, the flow occurs both with stabilised oscillatory radial bubble motion and transient cavity behaviour, due to an additional oscillating pressure gradient caused by turbulent velocity fluctuations (Fig. 3).

In addition, the magnitude of the permanent drop in pressure across the orifice is much higher compared with that across a venturi, resulting in a larger fraction of the energy being available for cavitation. Because of a higher contribution of the transient cavitation the cavitation intensity of an orifice system will be higher compared to a classical venturi (Ozonek and Lenik, 2011). Bubble dynamics simulations, using various operating/design 
parameters for the hydrodynamic cavitation reactor, have enabled definite trends to be established for the generated cavitation intensity. Ozonek (2012) investigated that the following considerable strategies have been defined for the design of hydrodynamic cavitation reactors:

An orifice flow configuration is more suitable for applications requiring intensive cavitation conditions. For milder processes which require collapsing pressure pulses between 15-20 bar and for transformations based on physical effects a venturi configuration is more convenient and energy efficient (Gogate and Pandit 2005).

Reducing the length of a venturi is the most economical technique for increasing cavitation intensity. But for higher flow rates there can be a limitation because of flow instability and super-cavitation possibilities.

A similar data can be used when reducing the venturi constriction to pipe diameter ratio (Gogate. 2010, Gogate and Pandit 2005).

For an orifice flow configuration the most convenient way to control the cavitation intensity is by controlling the orifice to pipe diameter ratio (basically throttling the pump discharge through a valve), or the crosssectional flow area by varying the number and the diameter of the perforations on the orifice plate. However, random growth of bubbles downstream from the orifice may cause splashing and vaporisation (supercavitation) (Gogate, 2010).

An option to have more intensive cavitation effect is to increase the pipe size downstream from the orifice. However, using pipes with a larger size requires higher volumetric flow rates to carry out the process using the same cavitation number, resulting in higher processing costs (Gogate and Pandit, 2005).
The degradation of persistent organic pollutants using hydrodynamic cavitation

Ozonek (2012) reported that a specific group of environmental pollutants, namely POPs (Persistent Organic Pollutants) and released into the environment, mainly from anthropogenic sources are characterised by their high toxicity, persistence and ability to bio-accumulate. This group of organic pollutants include, amongst others: polycyclic aromatic hydrocarbons (PAHs), chlorophenols, polychlorinated biphenyls (PCBs), dioxins PCDD (Polychlorinated Dibenzodioxins) and PCDF (Polychlorinated Dibenzofurans), and some pesticides. These compounds, depending on the part of a given ecosystem in which they occur (soil, benthal sludge deposits, surface water and groundwater) may undergo slow changes due to various physical, chemical, biological or even photochemical processes. Depending on the compound and medium in which they are found, as well as the environmental factors specific to the medium, decomposition processes occur at different rates, and the newly created compounds can create a burden on the environment to a greater or lesser extent. The two key mechanisms responsible for the degradation of organic pollutants using hydrodynamic cavitation are, the thermal decomposition/pyrolysis of organic pollutant entrapped in the cavities due to the generation of transient temperature pressure conditions, and secondly, the reaction of free radicals with the organic pollutant occurring at the cavitywater interface (Sivasankar and Moholkar 2009). They have concluded that the intensity and number of cavitation events can be effectively controlled by using different plates differing in number and diameter of holes. They have found that the flow geometry of the orifice plates considerably affects the rate of the iodine liberation. They have recommended that for the plates having the same flow area, it is advisable to use a plate with a smaller hole 
size, thereby increasing the number of holes (higher $\alpha$, the ratio of total perimeter of holes to the total area of the opening) to get the maximum cavitational effects (Pradhan and Gogate, 2010). Raut-Jadhav et al., (2016) revealed that the degradation of methomyl in a hydrodynamic cavitation reactor (HC) combined and intensifying agents such as $\mathrm{H}_{2} \mathrm{O}_{2}$, fenton reagent and ozone.

However, $\mathrm{pH}$ and inlet pressure were optimized to the cavitating device (circular venturi) to maximize the efficancy of hydrodynamic cavitation. At an optimum $\mathrm{pH}$ of 2.5 and optimum inlet pressure of 5 bar, hybrid processes have been applied to provide further degradation of methomyl. In all hybrid processes a significant synergistic effect was observed. After the combination of hydrodynamic cavitation with $\mathrm{H}_{2} \mathrm{O}_{2}$, fenton process and ozone, the synergetic coefficients were obtained as 5.8, 13.41 and 47.6 respectively. In terms of mineralization extent and energy efficiency, individual and hybrid processes' efficacy has also been obtained. The most effective process was $\mathrm{HC}+$ Ozone process with highest synergetic coefficient, energy efficiency and mineralization extent.

Moreover, prevents and reduces the cavitation damage the main measure to include:

Correct design hydraulic turbine runner, reduces the hydraulic turbine cavitation coefficient

Enhancement manufacture quality, the guarantee leaf blade's geometry shape and the relative position are correct, guarantee leaf blade surface smooth bright and clean.

Uses the anti-cavitation material, reduces the cavitation to destroy, and for example uses the stainless steel runner.

Calculates the installation elevation of hydraulic turbine correctly.
Improves the running condition, avoids the hydraulic turbine for a long time running under the low head and the low load. Usually does not allow the hydraulic turbine to transport under the low output

Prompt maintenance, and pays attention to the patching welding the polish quality, avoids the cavitation the malignant development.

Uses the air supplemental equipment to send the air into the draft tube, eliminates possibly has the cavitation oversized vacuum.

It is an acceptable method to use hydrodynamic cavitation to increase the biodegradability of organic compounds in polluted water and effluent (Ozonek 2012). The generation of hydroxyl radicals during this process, with the involvement of oxygen and/or air, can lead to the degradation of organic matter within the sewage and organic compounds in the polluted waters. In general, cavitation is one of the elements of an integrated treatment system, consisting of physical, chemical and biological processes. By decreasing the amount of persistent organic pollutants in wastewater treatment plant effluent, we will demonstrate the improved efficiency of treatment. Benito et al., (2005) also found that the potential of hydrodynamic cavitation as an AOP for wastewater treatment, showing its suitability and efficiency against a wide variety of contaminants (biodegradable, recalcitrant, organic and inorganic) and concentrations, with very low operation costs, simple equipments and no reactants required. Many researchers have reported that ultrasonic irradiation process was capable of degrading various recalcitrant organic compounds such as phenol compounds, chloroaromatic compounds, aqueous carbon tetrachloride, pesticides, herbicides, benzene compounds, polycyclic aromatic hydrocarbons and organic dyes. The frequency of ultrasound, irradiating 
surface, intensity of sound wave, calorimetric efficiency of ultrasonic equipment (power dissipated into the system per unit power supplied), physicochemical properties of the liquid medium and the presence of air and solid particles are the important parameters which affects the cavitational efficiency of acoustic cavitational reactor (Chakinala. 2009).

Korniluk and Ozonek (2011) reported that the application of hydrodynamic cavitation to landfill leachate treatment. Though the landfill leachate characterized by a high concentration of organic carbon and total nitrogen could be degraded by hydrodynamic cavitation, the degradation efficiency was relatively low. Only $6.7 \%$ of COD and $5.1 \%$ of TOC were removed after $30 \mathrm{~min}$ treatment. In order to generate higher quantum of oxidizing agents, the process based on hydrodynamic cavitation could be supplemented by other processes. Chakinala et al., (2008) hydrodynamic cavitation induced by a liquid whistle reactor in conjunction with AFP was used to deal with two kinds of industrial effluent, viz., phenolic compounds and pink dye stuffs. Under optimized conditions depending on the type of effluent samples, 60-70\% removal of TOC and $85 \%$ removal of COD were obtained. This demonstrates that the combination of hydrodynamic cavitation with AFP is also effective in real industrial wastewater treatment.

Kuppuswamy and Rudramoorthy (2005) reported that the deformation of outer distributor cone in the bulb turbine due to cavitation. Moreover, top and bottom sides of the outer distributor cone enlarged in size from the initial dimensions at the time of erection of the turbine. The left and right hand side dimensions reduced from the erection data. For the cavitation erosion phenomenon, the pressure waves- impact mechanisms is responsible for damage. Susan-Resiga et al.,
(2002) revealed that the initial cavitation number of a francis turbine runner and repair of cavitation pitting damage on turbines is considered an essential part of a hydro plant maintenance program. Raikwar and Jain (2017) reported that the cavitation completely in hydraulic turbines can be reduced to economic acceptable level. Some of the investigators have reported that in spite of design changes in the turbine components and providing different materials and coatings to the turbine blades, the improvement in most cases is not quite significant. It is therefore; required experimental and theoretical studies for studying the impact of cavitation in hydro turbine.

Wang et al., (2009) also found that the combination of $\mathrm{H}_{2} \mathrm{O}_{2}$ and jetinduced hydrodynamic cavitation to decompose aqueous solution of rhodamine B. An obvious synergetic effect between hydrodynamic cavitation and hydrogen peroxide has been reported. The relative amounts of $\bullet \mathrm{OH}$ radicals produced were detected by using TA as a fluorescent probe, and according to the results the production of $\cdot \mathrm{OH}$ radicals in hydrodynamic cavitation can be enhanced by $\mathrm{H}_{2} \mathrm{O}_{2}$ addition (Gogate, 2011).

This result suggests that the synergetic effect between hydrodynamic cavitation and $\mathrm{H}_{2} \mathrm{O}_{2}$ for the degradation of rhodamine $\mathrm{B}$ can basically be because of the contribution of additional $\bullet \mathrm{OH}$ radicals production. It has been also established that increased loading of $\mathrm{H}_{2} \mathrm{O}_{2}$, lower medium $\mathrm{pH}$, higher fluid pressures and lower initial dye concentration are more favourable for the degradation of rhodamine B. For temperature, increasing the temperature from $30-50^{\circ} \mathrm{C}$ has advantage to degradation of rhodamine $\mathrm{B}$, but at $60^{\circ} \mathrm{C}$ the degradation rate is lower. The degradation kinetics of rhodamine B were established and reported to follow a pseudo-first-order kinetics. 
Bagal and Gogate (2014). Reported that the acid condition can favor the generation of hydroxyl radicals due to the decomposition of hydrogen peroxide, and impede the recombination reaction among these free radicals. The effect of solution $\mathrm{pH}$ on the extent of degradation of diclofenac sodium was investigated by varying initial $\mathrm{pH}$ over the range of 4-7.5. It was observed that for a change in $\mathrm{pH}$ from 7.5 to 4 , the extent of degradation rose from $14.7 \%$ to $26.8 \%$. Similarly, the degradation experiment of imidacloprid showed that the maximum extent of degradation was obtained at an optimum $\mathrm{pH}$ of 3 . Under alkaline conditions, the extent of degradation was much lower than that under acidic conditions ( Patil et al., 2014).

Jyoti and Pandit (2004) also examined the viability of ozonation and cavitation for the disinfection of the heterotrophic plate count (HPC) bacteria and indicator microorganism in well water. It has been reported that when water is treated with $0.5 \mathrm{mg} / \mathrm{l}$ of ozone, $46 \%$ disinfection (in case of HPC bacteria) is achieved in the first $15 \mathrm{~min}$ of treatment, which in turn increases to $82 \%$ at the end of $60 \mathrm{~min}$. When $2 \mathrm{mg} / \mathrm{l}$ ozone is used in combination with hydrodynamic cavitation, the colony forming units (CFU) count reduces by $66 \%$ (5.17 bar) in the first $15 \mathrm{~min}$ of treatment as against $60 \%$ with ozone alone over $60 \mathrm{~min}$ which clearly indicates the significant effect of the combination of hydrodynamic cavitation and ozone. Nitrophenol is a toxic compound, which on entering into the body, even in small quantities, causes damage to the liver, kidney or the central nervous system. It appears in the effluent from the production of herbicides, insecticides, and synthetic dyes (Vasilieva et al., 2007, Batoeva et al., 2010). Its high stability and significant solubility in water are the causes of many difficulties in its decomposition during effluent treatment. The application of cavitation reactors, for this purpose, where oxidation processes are enhanced in the presence of hydroxyl radicals, is a promising technique for the degradation of nitrophenol and other phenols.

Pradhan and Gogate (2010) also observed that the removal of pnitrophenol with hydrodynamic cavitation, either individually or in combination with $\mathrm{H}_{2} \mathrm{O}_{2}$ and conventional Fenton process. An orifice plate and a venturi have been used and the effects of operating parameters such as initial concentration $(5 \mathrm{~g} / 1$ and $10 \mathrm{~g} / \mathrm{l})$, inlet pressure (5.7-42.6 psi) and $\mathrm{p}^{\mathrm{H}}$ (over a range 2-8) on the extent of removal has been investigated. Efficiency of removal using the combined approach was found to be strongly dependent on the operating $\mathrm{pH}$ and $\mathrm{pH}$ of 3.75 was found to be optimum. Under the optimized operating parameters, the degradation obtained using only $\mathrm{HC}$ was $53.4 \%$. The obtained results indicated that the extent of removal was marginally higher for the case of venturi $(53.4 \%$ removal) as compared to that obtained with orifice $(51 \%)$ for $5 \mathrm{~g} / \mathrm{l}$ initial $p$ nitrophenol concentration. For the combination of $\mathrm{HC}$ and $\mathrm{H}_{2} \mathrm{O}_{2}$, extent of removal increased to $59.9 \%$ with $0.5 \% \mathrm{H}_{2} \mathrm{O}_{2}$. In the case of combination of $\mathrm{HC}$ with Fenton chemistry, for $5 \mathrm{~g} / \mathrm{l}$ initial p-nitrophenol concentration, the maximum removal was $63.2 \%$ whereas for $10 \mathrm{~g} / \mathrm{l}$ initial concentration, the extent of degradation was $56.2 \%$. The mineralization of 2,4-dichlorophenoxyacetic acid by acoustic and hydrodynamic cavitation in conjunction with the advanced Fenton process. They have compared the efficacies of acoustic and hydrodynamic cavitation in enhancing the degradation process. It was observed that in $20 \mathrm{~min}$ of treatment time(beyond this time, the increase in the TOC removal is only marginal), the combination of acoustic cavitation and the advanced Fenton process gives around $60 \%$ TOC removal, whereas $70 \%$ TOC removal is observed with hydrodynamic cavitation combined with the 
advanced Fenton process. They have concluded that the use of zero-valent iron and hydrogen peroxide in conjunction with acoustic or hydrodynamic cavitation is a very effective means of destroying high concentrations of 2,4-dichlorophenoxyacetic acid. A combination of advanced Fenton process and cavitation has been observed to intensify the degradation process by way of turbulence and generation of additional free radicals. The results achieved using the hydrodynamic cavitation are particularly good in that this unit operates in a continuous mode and hence large volumes of contaminated water might be treated very cost-effectively particularly with low levels of polluted water, at equivalent energy dissipation levels (Bremner et al., 2008).

Bagal and Gogate (2013) reported that the degradation of 2, 4- dinitrophenol by using chemical and advanced oxidation processes in a combination of hydrodynamic cavitation. Under optimized operating parameters for hydrodynamic cavitation alone, it has been reported that only $12.4 \%$ degradation of 2 , 4dinitrophenol takes place in $120 \mathrm{~min}(\mathrm{~s})$ of reaction time. Significant intensification can be achieved when $\mathrm{HC}$ is combined with advanced oxidation processes such as conventional Fenton $\left(\mathrm{HC} / \mathrm{FeSO}_{4} / \mathrm{H}_{2} \mathrm{O}_{2}\right)$, advanced Fenton $\left(\mathrm{HC} / \mathrm{Fe} / \mathrm{H}_{2} \mathrm{O}_{2}\right)$ and Fentonlike process $\left(\mathrm{HC} / \mathrm{CuO} / \mathrm{H}_{2} \mathrm{O}_{2}\right)$. However, $100 \%, 54.1 \%$ and $29.80 \%$ degradation of 2,4dinitrophenol was obtained using combination of hydrodynamic cavitation with Fenton, advanced Fenton and Fenton-like processes respectively. Recently, a investigation on degradation of an aqueous solution of dichlorvos using hydrodynamic cavitation reactor gives the the effect of various additives such as hydrogen peroxide, carbon tetrachloride, and Fenton's reagent on the degradation rate with an aim of intensifying the degradation rate of dichlorvos using HC.
They have observed that use of hydrogen peroxide and carbon tetrachloride resulted in the enhancement of the extent of degradation at optimized conditions but significant enhancement was obtained with the combined use of hydrodynamic cavitation and Fenton's chemistry. The maximum extent of degradation as obtained by using a combination of hydrodynamic cavitation and Fenton's chemistry was $91.5 \%$ in $1 \mathrm{~h}$ of treatment time (Joshi and Gogate. 2012).

Gogate and Patil (2015) observed that the combination of hydrodynamic cavitation with Fenton's reagent improves the decomposition of triazophos giving $83.12 \%$ degradation. Optimum pressure of 5 bars and $\mathrm{pH}$ of 3 was found to be optimum for maximum degradation of triazophos using hydrodynamic cavitation alone.

Under the optimized operating conditions, hydrodynamic cavitation alone could not give complete degradation of triazophos. Due to its capability to generate highly reactive free radicals and turbulence the hydrodynamic cavitation is used effectively in water disinfection (Gaekwad and Patel 2015, Brahmbhatt. 2015).

Hydrodynamic cavitation also has a destructive effect on yeast, bacteria and even viruses. The neutralisation of microorganisms is caused both by the shockwaves, during cavitation bubble implosions, causing a tearing of the cell membrane, as well as by the production of hydrogen peroxide (Margulis. 1995). Cavitation is used for sludge pretreatment in wastewater treatment plants. It improves and accelerates the anaerobic digestion, which means higher biogas production, mass reduction, pathogen reduction and odour removal (Petkovšek. 2015). 
Table.1 Optimum operating conditions of hydrodynamic cavitation reactors

(Ozonek and Lenik, 2011)

\begin{tabular}{|c|c|c|}
\hline Item & Property & Favorable conditions \\
\hline 1 & Inlet pressure/Rotor speed of the equipment & 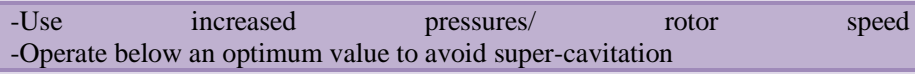 \\
\hline 2 & $\begin{array}{l}\text { Diameter of the constriction } \\
\text { e.g., hole diameter on the orifice plate }(11,21)\end{array}$ & $\begin{array}{l}\text {-Carry out an optimisation for the application } \\
\text {-Select higher diameters for applications which require intense cavitation } \\
\text {-Select lower diameters with a large number of holes for applications with } \\
\text { reduced intensity }\end{array}$ \\
\hline 3 & $\begin{array}{l}\text { Percentage of the free area for the flow i.e., the cross- } \\
\text { sectional area of holes on the orifice to the total cross- } \\
\text { sectional area of the pipe }\end{array}$ & -Use smaller free areas to produce high intensive cavitation. \\
\hline
\end{tabular}

Fig.1 Hydrodynamic cavitation

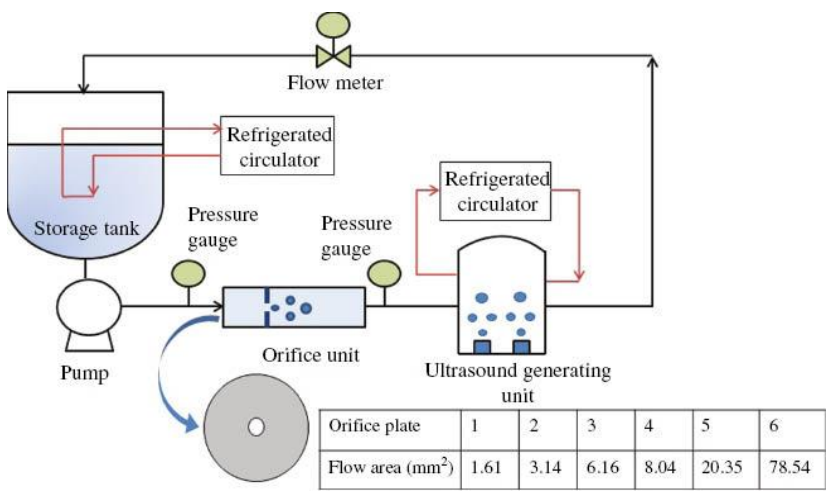

Fig.2 Intensity of the cavitation process (Gaekwad and Patel, 2015)

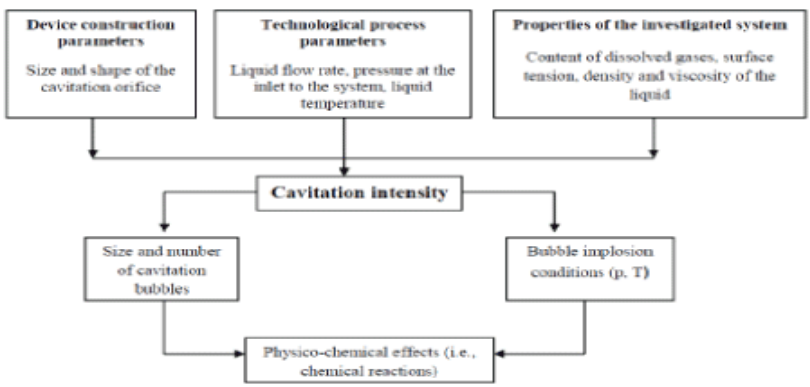

Fig.3 Orifice plates with different number and diameter of holes (Bagal and Gogate, 2014)

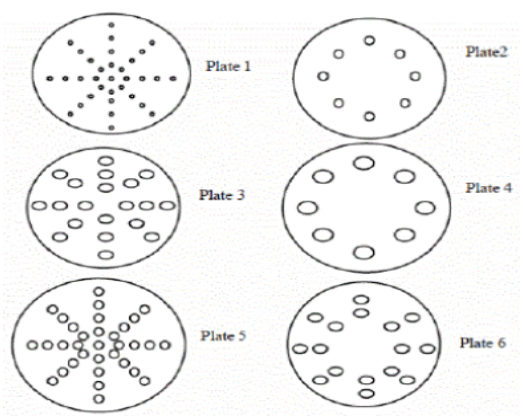


Sludge digestion is the process of destroying the sludge structures (rupturing cell membranes included), accelerating cell hydrolysis by releasing the cells' contents into the water present in the sludge, and allowing the initiation and increasing the level of biological decomposition (Zhang, 2007). The application of a sludge digester facilitates the hydrolysis stage producing methane (which is the essence of this process), and impacts on minimising the quantity of sludge remaining for final disposal. Sludge digestion can be used to enhance the effectiveness of the biological decomposition processes for sludge (including accelerating methane production, increasing gas production, increasing the digestion level, shortening the digestion time) by increasing the cells' hydrolysis rate and increasing the decomposition of low biodegradable substances (Gronroos et al., 2005). A high technological effectiveness allows intensifying biogas production by using hydrodynamic cavitation. Which used recycled activated sludge from the sewage treatment works, using advanced biological processes in the treatment of effluent, dependent on the simultaneous removal of organic compounds as well as nitrogen and phosphorus compounds?

The application of hydrodynamic cavitation in sewage treatment may be considered in two aspects:

The breakdown of various pollutants as a result of the specific conditions inherent in the cavitating liquid.

The combined interaction of the mechanical effects of hydrodynamic cavitation and oxidation, through the joint action of cavitation with the oxidants (Ozonek. 2012).

During the digestion (destruction) of the activated sludge cells, under cavitation conditions, into the solution of the surrounding liquid, the accumulated organic compounds and enzymes inside the cells are released, which impact the COD value (by raising it) and the products of hydrolytic decomposition. Comparing the digestion results for activated sludge it can be seen that the amount of biogas produced rose by $20 \%$ when hydrodynamic digestion was used. The study results confirmed that digestion strongly affects the amount of biogas produced, resulting in a lower dry solid content, and consequently less sludge for final disposal. The positive effect of digestion is a greater susceptibility of the sludge to drain.

\section{Economic Assessment of Hydrodynamic Cavitation Compared With Traditional Method}

A successful and economical design for a cavitation reactor requires an effective conversion of mechanical, electrical, or optical energy into the energy required to break chemical bonds. The first major step is the conversion of mechanical, electrical, or optical energy into the energy required for the formation of cavities. For hydrodynamic cavitation, this is the local pressure reduction sufficient to form cavities. In a hydrodynamic cavitation reactor, the pressure loss through expansion is the major source of energy loss. The associated pumping cost is a major issue for the economics of the process. There is also energy loss associated with the formation and implosion of the cavities.

In hydrodynamic cavitation, there is a substantial energy loss in the fluid pumping process. The loss depends on the flow rate as well as the pressure level. Different pressures and different flow rates will require different types of pumps. The energy efficiency associated with cavity implosion in hydrodynamic cavitation will depend on the level of turbulence in the flow. For example, orifices with small diameters will cause larger 
pressure drops but also larger turbulence downstream, which will allow a larger amount of energy to be released during the cavity implosion (Ozonek, 2012).

General economic method dealing with organic compound degradation is the biochemical method. However, some components such as polyethylene terephthalate (PET), polyvinyl alcohol (PVA) and some dispersed dyes are bio-refractory or toxic. Such kind of industrial water has a low $\mathrm{BOD} / \mathrm{COD}$ value and an unsuitable $\mathrm{pH}$ value for biochemical degradation.

A simple method to evaluate the economics of hydrodynamic cavitation in wastewater treatment is to calculate its operation cost.

First of all, we suppose the discharge standard is $95 \%$ of pollutant degradation. According to most previous investigations, the degradation kinetics of hydrodynamic cavitation obeys the first-order law, given as:

In $\mathrm{C} / \mathrm{C} 0=-\mathrm{kt}(6.1)$

Where $\mathrm{C}(\mathrm{mg} / \mathrm{L})$ is the pollutant concentration at time t, $\mathrm{C} 0(\mathrm{mg} / \mathrm{L})$ is initial concentration of pollutant and $\mathrm{k}$ (min-1) is the rate constant (Mehrjouei et al., 2011). The time for $95 \%$ degradation in cavitation reaction zone is:

$\mathrm{t} 95(\min )=2.996 / \mathrm{k}(6.2)$

Electric energy (power) in kilowatt hours $(\mathrm{kWh})$ required for $95 \%$ degradation is (Adewuyi and Peters 2013).

$\mathrm{E}(\mathrm{kWh})=\mathrm{Pm} \times \mathrm{t} 95 / 60 \times 1000(6.3)$

If the price of electricity is $\mathrm{P}^{*} \$ / \mathrm{kWh}$, the operation cost of hydrodynamic cavitation system would be:

$\mathrm{C} 1=\mathrm{E} . \mathrm{P}^{*}(6.4)$
It should be noted that Pm and $\mathrm{k}$ are related with the volume of the pollutant, the geometry and operation conditions of the system (Tao et al., 2016).

Amongst the hydrodynamic cavitation equipments, high speed and high-pressure homogenizers (typically laboratory-scale equipment with capacity of 1.5 and 2.01 respectively) have energy efficiency of 43 and $54 \%$ respectively (Gogate et al., 2006). The orifice type of hydrodynamic cavitation reactor having a capacity of 501 (typically a pilot plant scale) has an observed energy efficiency of $60 \%$. Conventionally speaking, hydrodynamic cavitation equipment are more energy-efficient compared to the acoustic counterparts (except for the multiple frequency flow cells), though the exact cavitational effects may or may not follow similar trends, as the fraction of this energy utilized for the cavitational activity is different (Gogate et al., 2006).

Thanekar and Gogate (2018) reported that the degradation of different pollutants, such as pharmaceuticals, pesticide, phenolic derivatives and dyes, as well as the treatment of real industrial effluents using hybrid methods based on $\mathrm{HC}$ viz. $\mathrm{HC} / \mathrm{H}_{2} \mathrm{O}_{2}$, HC/Ozone, HC/Fenton, HC/Ultraviolet irradiations (UV), and $\mathrm{HC}$ coupled with biological oxidation. Furthermore, recommendations for the selection of optimum operating parameters, such as inlet pressure, solution temperature, initial $\mathrm{pH}$ and initial pollutant concentration in order to maximize the process intensification benefits.

Moreover, hybrid methods based on HC has been demonstrated to show good synergism as compared to individual treatment approach. Overall, high energy efficient wastewater treatment can be achieved using a combined treatment approach based on $\mathrm{HC}$ under optimized condition. 
Hydrodynamic cavitation is a new, advanced technology for the decomposition of complex compounds and an alternative to ultrasoundinduced cavitation. The use of hydrodynamic cavitation in recent technologies can conserve soil and water and allows processes to be greatly effective during water and effluent treatment. A technology which utilises the cavitating liquid environment can be considered as a non-waste technology and environmentally friendly due to the possibility of degradation of low biodegradable, hazardous and carcinogenic organic compounds, which are resistant to conventional disposal methods. Examples include pesticides, dyes, or high molecular organic compounds, which in the cavitating liquid environment become susceptible to biodegradation. Hydrodynamic cavitation can generate high-temperature and high pressure conditions which lead to the dissociation of water molecules and the release of active radicals. Many of the chemical transformations take place under these conditions. Both the magnitudes of pressure and temperature and the number of free radicals are affected by the geometrical and operating parameters. Optimization of these parameters using theoretical analysis as well as laboratory-scale study is always recommended before putting the new technology into practice.

The hydrodynamic cavitation reactors offer $100 \%$ scale up potential as compared to the ultrasonic reactors for the destruction of complex pollutants. The combination of $\mathrm{HC}$ with other AOPs is found to be more efficient than the individual technique, as the combination generates more $\mathrm{OH}$ radicals, thus intensifying the degradation. Hydrodynamic cavitation has the possible to become energy efficient technique. It is difficult to avoid cavitation completely in hydraulic turbines but can be reduced to economic acceptable level. It can diminish recently necessary use of expensive chemical reagents for advanced treatment process. These chemicals create additional problems when deposited into environment. Finally, as nowadays a lot of attention is put upon micro pollutants such as endocrine disrupting compounds, it is expected that developed process of wastewater treatment with aid of cavitation will considerably reduce their presence in purified water and also help in soil and water conservation.

\section{References}

Adewuyi YG, Peters RW (2013) Fundamental developments and economic feasibility of AOPS involving ultrasound for environmental remediation.

Amin LP, Gogate PR, Burgess AE, Bremner DH (2010) Optimization of a hydrodinamic cavitation reactor using salicyclic acid dosimetry. Chemical engineering journal 156: 165-169.

Arrojo S, Benito Y (2008) A theoretical study of hydrodynamic cavitation. Ultrasonsonochem 15: 203-211.

Bagal MV, Gogate PR (2013) Degradation of 2, 4-dinitrophenol using a combination of hydrodynamic cavitation, chemical and advanced oxidation processes. Ultrason. Sonochem 20: 1226-1235.

Bagal MV, Gogate PR (2014) Wastewater treatment using hybrid treatment schemes based on cavitation and Fenton chemistry: a review. Ultrasonics Sonochemistry 21: 1-14.

Bagal, MV, Gogate PR (2014) Degradation of diclofenac sodium using combined processes based on hydrodynamic cavitation and heterogeneous photocatalysis. Ultrason. Sonochem, 21: 1035-1043.

Batoeva AA, Khandarkhaeva MS, Sizykh MR, Ryazantsev AA (2010) Cavitional activation of the galvanochemical oxidation of phenol. Russian journal of 
applied chemistry 83: 72-75.

Benito, Y., S. Arrojo, G. Hauke and P. Vidal. 2005. Hydrodynamic Cavitation as a low-cost AOP for wastewater treatment: preliminary results and a new design approach. Water Resources Management III. 80: 495- 503.

Brahmbhatt JI, Patel RL (2015) Treatability study of pharmaceutical wastewater by hydrodynamic cavitation process. International journal of engineering research and general science 3: 74-78.

Bremner, D. H., Carlo, S. D., Chakinala, A. G., Cravotto, G (2008) Mineralization of 2,4 dichlorophenoxyacetic acid by acoustic or hydrodynamic cavitation in conjunction with the advanced Fenton process. Ultrasonics Sonochemistry, 15: 416-419.

Cai J, Huai X, Li X (2009) Dynamic behaviors of cavitation bubble for the steady cavitating flow. Journal of Thermal Science 18: 338-344.

Chakinala GA, Gogate PR, Burgess AE, Bremnera DH (2009) Industrial wastewater treatment using hydrodynamic cavitation and heterogeneous advanced Fenton processing, Chemical Engineering Journal, 152: 498-502.

Chakinala, AG., Gogate, PR., Burgess, A. E., Bremner, DH (2008) Treatment of industrial wastewater effluents using hydrodynamic cavitation and the advanced Fenton process. Ultrason. Sonochem.1: 49-54.

Chanda SK (2012) Disintegration of sludge using ozone-hydrodynamic cavitation. Electronic theses and dissertations (ETDs).

Dular M, Griessler-Bulc, T, Gutierrez-Aguirre I, Heath E, Kosjek T, et al., (2016) Use of hydrodynamic cavitation in (waste) water treatment. Ultrasonics Sonochemistry 29: 577-588.

Franc JP, Michel JM (2006) Fundamentals of cavitation. Springer science \& business media, Germany.

Franke M, Braeutigam $\mathrm{P}, \mathrm{Wu} \mathrm{Z}$, Ren $\mathrm{Y}$, Ondruschka B (2011) Enhancement of chloroform degradation by the combination of hydrodynamic and acoustic cavitation. UltrasonSonochem 18: 888-894.

Gaekwad RR, Patel RL (2015) Pesticide wastewater treatment by hydrodynamic cavitation process. International journal of advance research in engineering, science \& technology (IJAREST).

Gogate PR (2007) Application of cavitational reactors for water disinfection: current status and path forward. Journal of environmental management 85: 801815.

Gogate PR (2008) Cavitational reactors for process intensification of chemical processing applications: a critical review. Chemical engineering and processing: process intensification 47: 515-527.

Gogate PR (2010) Application of hydrodynamic cavitation for food and bioprocessing. Ultrasound technologies for food and bioprocessing, Springer, New York, pp: 141-173.

Gogate PR (2011) Cavitation in Biotechnology. Engineering fundamentals of biotechnology 2: 957965.

Gogate PR (2011) Hydrodynamic cavitation for food and water processing. Food and bioprocess technology 4: 996-1011.

Gogate PR, Kabadi AM (2009) A review of applications of cavitation in biochemical engineering/biotechnology. Biochemical engineering journal 44: 6072.

Gogate PR, Pandit AB (2000) Engineering designs methods for cavitation reactors II: hydrodynamic cavitation. AIChE journal 46: 1641-1649.

Gogate PR, Pandit AB (2005) A review and 
assessment of hydrodynamic cavitation as a technology for the future. Ultrasonics Sonochemistry 12: 21-27.

Gogate PR, Patil PN (2015) Combined treatment technology based on synergism between hydrodynamic cavitation and advanced oxidation processes. Ultrasonics sonochemistry 25: 60-69.

Gogate PR, Tayal RK, Pandit AB (2006) Cavitation: a technology on the horizon. Current science 91: 35-46.

Gronroos A, Kyllonen H, Korpijarvi K, Pirkonen $\mathrm{P}$, Paavola $\mathrm{T}$, et al., (2005) Ultrasound assisted method to increase soluble chemical oxygen demand (SCOD) of sewage sludge for digestion. Ultrasonics sonochemistry 12: $115-120$.

Iftikhar, Ahmad, Syed Asif, Ali and Barkatullah (2007), Elements of an effective repair program for cavitation damages in hydraulic turbines. Information Technology Journal, 6(8): 1276-1281.

Joshi, R. K., Gogate, P. R. (2012) Degradation of dichlorvos using hydrodynamic cavitation based treatment strategies. Ultrasonics Sonochemistry, 19, 532-539.

Jyoti KK, Pandit AB (2004) Ozone and cavitation for water disinfection. Biochemeng J 18: 9-19.

Korniluk, M., Ozonek, J (2011) Application of hydrodynamic cavitation for leachate of municipal landfill site. In The $8^{\text {th }}$ International Conference Environmental Engineering, Cygas, D., Froehner, K. D., Eds. Vilnius Gediminas Technical Univ Press, Technika: Vilnius-40; Vol. 2, pp 584-587.

Kuppuswamy N, and Rudramoorthy R (2005), Deformation of outer distributor cone in bulb turbine due to cavitationA case study, Journal of Scientific \& Industrial Research, 64, pp. 256-261.
Margulis MA (1995) Sonochemistry and cavitation. Gordon and Breach Publishers, Amsterdam.

Martin MJ, Artola A, Balaguer MD, Rigola M (2003) Activated carbons developed from surplus sewage sludge for the removal of dyes from dilute aqueous solutions. ChemEng J 94: 231-239.

Mehrjouei M, Müller S, Möller D (2011) Degradation of oxalic acid in a photocatalytic ozonation system by means of Pilkington Active TM glass. Journal of photochemistry and photobiology A: Chemistry 217: 417424.

Moholkar VS, Pandit AB (2001) Modeling of hydrodynamic cavitation reactors: a unified approach. Chemical engineering science 56: 6295-6302.

Ozonek J (2012) Application of hydrodynamic cavitation in environmental engineering. Taylor \& Francis Group, London.

Ozonek J, Lenik K (2011) Effect of different design features of the reactor on hydrodynamic cavitation process. Arch Mater SciEng 52: 112-117.

Pandit AB, Mukherjee AC, Kasat GR, Mahulkar AV (2011) Method of designing hydrodynamic cavitation reactors for process intensification. US Patent Application No.12/992,038.

Patil PN, Bote SD, Gogate PR (2014) Degradation of imidacloprid using combined advanced oxidation processes based on hydrodynamic cavitation. Ultrason. Sonochem. 21: 1770-1777.

Pehkonen T, Ranta H, Tolvanen A, Laine K (2002) The frequency of the fungal pathogen Exobasidiumsplendidum in two natural stands of the host Vacciniumvitis-idaea in the subarctic timberline area. Arctic, Antarctic and Alpine Research 34: 428-433.

Petkovšek M, Mlakar M, Levstek M, Strazar M, Širok B, et al., (2015) A novel 
rotation generator of hydrodynamic cavitation for waste-activated sludge disintegration.

Ultrasonics sonochemistry 26: 408-414.

Pilli S, Bhunia P, Yan S, LeBlanc RJ, Tyagi RD, et al., (2011) Ultrasonic pretreatment of sludge: a review. Ultrasonics sonochemistry 18: 1-18.

Pradhan AA, Gogate PR (2010) Removal of p-nitrophenol using hydrodynamic cavitation and Fenton chemistry at pilot scale operation. ChemEng J 156: 77-82.

Raikwar, A. S and Jain, A. 2017. A Review Paper on Hydrodynamic Cavitation. International Journal of Engineering Science and Computing. 7(4): 1029610299.

Raut-Jadhav S, Saini D, Sonawane S, Pandit A (2016) Effect of process intensifying parameters on the hydrodynamic cavitation based degradation of commercial pesticide (methomyl) in the aqueous solution. Ultrasonics sonochemistry 28: 283-293.

Santa JF, Espitia LA, Blanco JA Romo, Toro SA (2009), Slurry and cavitation erosion resistance of thermal spray coatings. International journal of Wear 267, pp. 160-167.

Shah YT, Pandit AB, Moholkar VS (2012) Cavitation reaction engineering, Springer Science \& Business Media, Germany.

Sivasankar T, Moholkar VS
(2009) Mechanistic approach to intensification of sonochemical degradation of phenol. ChemEng J 149: 57-69.

Susan-Resiga, RF Muntean, S Anton I (2002), Numerical analysis of cavitation inception inFrancis turbine. Proceedings of the 21st IAHR Symposium on Hydraulic Machinery and Systems.

Tao Y, Cai J, Huai X, Liu B, Guo Z (2016) Application of hydrodynamic cavitation into wastewater treatment: a review. Chemical engineering \& technology.

Thanekar, P and Gogate, P. 2018. Application of Hydrodynamic Cavitation Reactors for Treatment of Wastewater Containing Organic Pollutants: Intensification Using Hybrid Approaches. Fluids. 3(9): 1-24.

Vasilieva NB, Ryazantsev AA, Batoeva AA (2007) Nitrophenol oxidation in water with the use hydrodynamic cavitation. Chemistry for sustainable development 15: 705-710.

Wang X, Wang J, Guo P, Guo W, Wang C (2009) Degradation of rhodamine $B$ in aqueous solution by using swirling jetinduced cavitation combined with $\mathrm{H}_{2} \mathrm{O}_{2}$. J hazard mater 169: 486-491.

Zhang G, Zhang P, Yang J, Chen Y (2007) Ultrasonic reduction of exceed sludge from the activated sludge system. J hazard mater 145: 515-519.

\section{How to cite this article:}

Sharath Chandra, M., R.K. Naresh, N.C. Mahajan, Rajendra Kumar, Arvind Kumar, S.P. Singh, Yogesh Kumar and Rahul Indar Navsare. 2019. A Review on Hydrodynamic Cavitation - A Promising Technology for Soil and Water Conservation in Inceptisol of North West IGP. Int.J.Curr.Microbiol.App.Sci. 8(08): 739-753. doi: https://doi.org/10.20546/ijcmas.2019.808.084 